\title{
Editorial: Uncovering brand gremlins and other hidden perils
}

Like Mr Spock in Star Trek, marketers want their brands to 'live long and prosper'. Although particular products may come and go, properly managed brands can last for many generations. Yet some brands seem inexplicably to lose their momentum and profitability; a few even die prematurely. Many organisations are not even aware their brands are heading for trouble until it is too late. The critical question is, 'What needs to be done to keep brands healthy for the long run?'

Most perils to brand health can be partitioned into two categories. The first includes different types of brand crises, which are highly visible events that warrant considerable management attention. The second category of perils consists of brand gremlins, which are imperceptible in most organisations and therefore receive little management attention. Brand gremlins are the people and processes responsible for seemingly small but repetitive mishaps with customers, or for other activities that progressively undermine a brand.

The effects of brand gremlins on the brand are often hidden and incidental, and may, therefore, remain undetected for a long time. The underlying problems may surface only when the brand's health succumbs to the cumulative damage (like termite infestations or viral infections). To preserve long-term brand health, managers should make ongoing, concerted efforts to prepare for brand crises and deal with brand gremlins.

\section{BRAND CRISES}

Brand crises usually result from sudden, unexpected, large-scale events that have a significant impact on the brand, such as substantial shifts in customer demand, quantum changes in technology, or great natural or man-made disasters. Such events may have serious and lasting consequences for those brands that cannot absorb the shock or adapt quickly enough.

For example, continuing international conflicts, recent terrorist attacks, SARS outbreaks and economic downturns have reduced demand for air travel. This has driven many airlines to extinction (Sabena, Swissair and TWA, for example). Nevertheless, several carriers like Southwest Airlines, newcomer JetBlue and others continue to prosper.

Technological advances can precipitate another type of crisis when a brand's products or services become obsolete. The digital revolution in photography, video, music and communications poses huge challenges for brands that are tightly coupled with outdated product features and functions. While Epson is successfully shedding its earlier brand association with dot-matrix printers, the Polaroid brand seems to be fading along with the instant photography business. Meanwhile, Kodak is actively reorienting its venerable brand from film-based photography to the digital world.

Natural and man-made disasters can also jeopardise brands. The widespread crises of confidence in brands like Arthur Andersen, Enron, Firestone, Perrier and Snow Milk have led to steep sales declines or collapse. Some brands try to escape the past by adopting 
new names (for example, Valujet became AirTrans). Only a few brands like Tylenol survive such catastrophic events, recover with their reputations intact, and continue to thrive.

Andrew Grove, the former CEO and chairman of Intel, describes how to avert many brand crises by recognising strategic inflection points where the fundamentals of a business are about to change: ${ }^{1}$

'That change can mean an opportunity to rise to new heights. But it may just as likely signal the beginning of the end ... A strategic inflection point can be deadly when unattended to. Companies that begin a decline as a result of its changes rarely recover their previous greatness.'

A strong brand itself is not always enough to survive when the rules of the game are about to change. For example, slide-rules had been used for scientific and engineering calculations since the 1600s. Well-respected brands like Keuffel \& Esser, Pickett and others dominated the slide-rule market from the late 1800s until July 1972 when Hewlett-Packard introduced the HP-35, the first handheld electronic calculator to perform logarithmic and trigonometric functions. A few months later in 1973, Texas Instruments launched the inexpensive SR-50 slide-rule calculator and ultimately changed the rules of the game forever. Keuffel \& Esser was never able to leverage its great brand with electronic calculators and manufactured its last slide-rule in 1975; the company subsequently folded in 1987.

Far-sighted managers prepare and train their organisations to respond and manage brand crises. But they also use scenario planning and other exercises to understand their brand's weaknesses and identify strategic inflection points. With such insights and advanced planning, the managers at Keuffel \& Esser might have been able to take timely actions to pre-empt the crisis and preserve their brand.

The early recognition of strategic inflection points explains why some brands prosper while others do not fare as well in brand crises. Grove ${ }^{2}$ offers further practical advice on leveraging crisis points to a brand's advantage.

\section{BRAND GREMLINS}

Everyday events may be even more harmful to a brand's long-term health. Brand gremlins are those people, processes and other entities that are out of alignment with the organisation's overall brand strategy. Brand gremlins frequently lead to brand deterioration and an erosion of customer goodwill. Like vehicle wheels out of alignment, sand in the gears of machinery, bugs in a software program, or other recurring glitches, the underlying cause of a brand problem may be scarcely noticeable, but the collective effects can be devastating if not discovered and corrected early enough.

The following list describes six common types of brand gremlin:

- Loss of trust

- Loss of esteem

- Loss of distinctiveness

- Loss of value

- Loss of relevance

- Loss of distribution.

These types are neither mutually exclusive nor exhaustive: brand gremlins may possess multiple traits, and 
other types of gremlins also exist (see, for example, Jones and Sasser ${ }^{3}$ ). Readers are invited to share their experiences about brand gremlins and make suggestions for updating this initial list by contacting the author at: peterfarquhar@foxstrategy.com.

\section{Loss of trust}

Trust gremlins do not fulfil the brand's promise or keep their personal word to customers.

Examples: A hotel reservation clerk who guarantees specific accommodation to guests calling in advance, but is unaware the hotel staff do not honour these commitments at check in; a motor vehicle dealer who charges for repairs not done; the service person who, without explanation, misses a critical appointment; or a mail-order product that does not perform as advertised.

Effects: Customers usually blame the brand for such shortcomings and may then warn others that the brand cannot be trusted. Brand loyalty begins to evaporate quickly as customers defect and negative word of mouth spreads.

\section{Loss of esteem}

Esteem gremlins spoil the brand's emotional appeal for customers.

Examples: A romantic restaurant where your companion is served a bowl of soup with a fly in it; a family theme park where several children's attractions are unexpectedly closed for the day; an up-market department store with hard-to-find sales people; or a medical specialist's office with a careless, indifferent receptionist.

Effects: As customers' admiration and respect for the brand diminishes, they will no longer recommend the brand to others. At some point, customers might seek other alternatives and regretfully switch to other brands.

\section{Loss of distinctiveness}

Distinctiveness gremlins dilute the brand's point of difference and thus blur its image with customers.

Examples: A leading brand of pain reliever introduces scores of extensions to cold and fever remedies, speciality medications and other product categories; a snack brand's cluttered packaging promotes its branded ingredients, other branded snacks, movie rentals, soft drinks and logo clothing; a well-known bank co-locates inside local food chains to offer financial, insurance, investment, real estate, travel and other services.

Effects: Confused customers no longer understand the brand's meaning and core benefits. The brand's comparative advantages will be diluted if category extensions do not fit well with the brand or if other marketing actions make customers' decisionmaking more complicated. Customers may then either switch to more clearly differentiated brands or put more emphasis on price in choosing among brands.

\section{Loss of value}

Value gremlins lower a brand's perceived quality and the functional benefits offered to customers.

Examples: A local bakery substitutes cheaper materials, cuts product sizes and offers less variety; a shoe manufacturer reduces the number of widths offered to just 'narrow' and 'wide' shoes; a bank no longer returns personal cheques with 
customers' monthly account statements; or a general merchandiser, after many successful years, eliminates its signature lifetime warranty.

Effects: As perceived quality slips, customers eventually decide the brand does not offer them fair value. Customers are then reluctant to pay much of a premium for the brand. If the brand continues to lose value, it becomes a commodity in customers' minds and must compete on price to survive.

\section{Loss of relevance}

Relevance gremlins fail to meet critical changes in customers' needs or expectations.

Examples: A family people-carrier has no drinks cup holders; a popular food is manufactured with unhealthy cooking oils; a shopping mall's car park is dimly lit at night; or an online merchant warns customers it is not responsible for safeguarding their personal information or credit card transactions.

Effects: Without a clear understanding of customer expectations or emerging trends in the market, some organisations are relatively slow in meeting customer needs. Customers often regard such brands as no longer appropriate and eliminate them from further consideration in their purchasing decisions.

\section{Loss of distribution}

Distribution gremlins reduce a brand's availability to customers.

Examples: A vending machine has frequently sold out of a brand; a large bank closes several convenient branches and cashpoint machines; a leading retailer manages its inventory costs by carrying only a few brands and popular items within a brand line; or a technical service centre is open for customers' calls only a few hours each weekday afternoon.

Effects: Customers who repeatedly discover their preferred brand is not carried, is back-ordered or out of stock will either find available brands to buy or use alternative ways to satisfy their needs. A brand's power in the marketplace depends on its awareness and availability to customers.

Marketers' blind spots can make it difficult to detect brand gremlins and other hidden perils. Blind spots may obscure essential information from an individual or organisation, which is unaware that anything is missing. The secret to uncovering blind spots is to use multiple sources of information and find reliable ways of systematically challenging established beliefs. Resourceful marketers first take steps to learn about their blind spots before searching for brand gremlins. Farquhar ${ }^{4,5}$ examines several kinds of blind spot to improve marketers' discovery of various threats to their brand's health.

Knowing how to spot, and where to look for, brand gremlins is just the start. The next challenge is to align the organisation around a winning brand strategy and turn gremlins into advocates for the brand. Porter ${ }^{6}$ illustrates how to align operational and other elements in a cohesive brand strategy. By preparing for brand crises and transforming brand gremlins, organisations are far more likely to see their brands live long and prosper.

Peter Farquhar Editorial Board 


\section{References}

(1) Grove, A. S. (1996) 'Only the Paranoid Survive: How to Exploit the Crisis Points that Challenge Every Company', Doubleday, New York, NY, pp. 3-4.

(2) Ibid.

(3) Jones, T. O. and Earl Sasser, W. Jr, (1995) 'Why satisfied customers defect', Harvard Business Review, November-December, pp. 88-99.
(4) Farquhar, P. H. (1999) 'The mysteries of branding revealed', Journal of Brand Management, Vol. 7, No. 1, pp. 4-7.

(5) Farquhar, P. H. (2003) 'Discover the blind spots in your brand vision', Marketing Management, Vol. 12, No. 3, pp. 18-25.

(6) Porter, M. (1996) 'What is strategy?', Harvard Business Review,

November-December, pp. 61-78. 